\title{
Analgesic efficacy and safety of epidural oxycodone in patients undergoing total hip arthroplasty: a pilot study
}

This article was published in the following Dove Press journal:

Journal of Pain Research

27 September 2017

Number of times this article has been viewed

\author{
Bogumił Olczak' \\ Grzegorz Kowalski',2 \\ Wojciech Leppert ${ }^{2}$ \\ Agnieszka Bienert ${ }^{3}$ \\ Artur Teżyk ${ }^{4}$ \\ Michał Adamski' \\ Stanisław Rzymski' \\ Katarzyna \\ Wieczorowska-Tobis ${ }^{2}$ \\ 'Department of Anaesthesiology, \\ Józef Struś Multiprofile Municipal \\ Hospital, Poznań, 2Department of \\ Palliative Medicine, ${ }^{3}$ Department of \\ Clinical Pharmacy and Biopharmacy, \\ ${ }^{4}$ Department of Forensic Medicine, \\ Poznan University of Medical Sciences, \\ Poznań, Poland
}

Background and objectives: Oxycodone is poorly studied as an adjuvant to central blockades. The aim of this pilot study was to assess the efficacy and safety of oxycodone hydrochloride in epidural blockade among patients undergoing total hip arthroplasty (THA).

Patients and methods: In 11 patients (American Society of Anesthesiologists physical status classification system II/III, age range: 59-82 years), THA was conducted with an epidural blockade using $15 \mathrm{~mL} 0.25 \%$ bupivacaine $(37.5 \mathrm{mg}$ ) with $5 \mathrm{mg}$ oxycodone hydrochloride and sedation with propofol infusion at a dose of 3-5 mg/kg/h. After the surgery, patients received ketoprofen at a dose of $100 \mathrm{mg}$ twice daily. In the first 24 hours postoperative period, pain was assessed by numerical rating scale at rest and on movement; adverse effects (AEs) were recorded; and plasma concentrations of oxycodone, noroxycodone, and bupivacaine were measured.

Results: The administration of epidural oxycodone at a dose of $5 \mathrm{mg}$ in patients undergoing THA provided analgesia for a mean time of $10.3 \pm 4.89 \mathrm{~h}$. In one patient, mild pruritus was observed. Oxycodone did not evoke other AEs. Plasma concentrations of oxycodone while preserving analgesia were $>2.9 \mathrm{ng} / \mathrm{mL}$. Noroxycodone concentrations in plasma did not guarantee analgesic effect.

Conclusion: The administration of epidural oxycodone at a dose of $5 \mathrm{mg}$ prolongs the analgesia period to $\sim 10$ hours in patients after THA. Oxycodone may evoke pruritus. A $5 \mathrm{mg}$ dose of oxycodone hydrochloride used in an epidural blockade seems to be a safe drug in patients after THA. Keywords: analgesia, oxycodone, pain, total hip arthroplasty

\section{Introduction}

In recent times, the number of patients who require joint arthroplasty due to advanced coxarthrosis has significantly increased. The majority are patients who undergo total hip arthroplasty (THA). Approximately 47,000 THA surgical procedures are done annually in Poland across both sexes with similar frequencies, and most frequently between 60 and $\geq 90$ years of age. ${ }^{1}$ Apart from advanced coxarthrosis, these patients often have other underlying comorbid conditions, the most frequent being hypertension, diabetes, and heart failure at different stages. THA is one of the most burdensome orthopedic procedures in terms of extent and number of complications. Presence of the best conditions for surgery provides a basis for a quick return of patients to health - one of the important elements is effective intra- and postoperative analgesia.

The safest anesthesia methods have been sought for this type of surgery for many years. Spinal and epidural anesthesia are among the most frequently utilized, and these may be used either alone or in a "composite" manner - spinal blockade with epidural
Correspondence: Wojciech Lepper Department of Palliative Medicine, Poznan University of Medical Sciences, Osiedle Rusa 55, 61-245 Poznań, Poland Tel/Fax +48 6I 8738303

Email wojciechleppert@wp.pl 
catheter insertion for a continuous postoperative analgesia. Because of the time taken for surgery ( 1.5-2 hours) and inconvenient patient position, a central blockade is often combined with concurrent sedation or general anesthesia with benzodiazepines, propofol, or anesthetic gases. In order to prolong the analgesic effect of a central blockade, different adjuvants are used, among other opioids. Although these provide a beneficial effect in terms of prolonging analgesia, they are associated with several, occasionally severe, adverse effects (AEs). ${ }^{2}$

The first study on spinal route of opioid administration was presented in Paris in 1901 by a Romanian surgeon, Racoviceanu-Pitesti, who used morphine concurrently with cocaine. ${ }^{3}$ Morphine was used for the next several decades without recognition of its mechanism of action until 1973, when opioid receptors were identified in the spinal cord. ${ }^{4}$ Wang et al in 1979 administered morphine through the spinal route for palliative cancer treatment. ${ }^{5}$ The same year, Behar et al published the first study on the epidural route of morphine administration for pain treatment. ${ }^{6}$ Apart from prolonging the postoperative analgesia period, it was noticed that using different opioids in central blockades decreases their dose and limits the number of AEs associated with systemic administration. ${ }^{2}$

There have been several studies on using opioids for central blockades, in particular morphine, fentanyl, and sufentanyl. ${ }^{2,3,5}$ For many years, morphine has been the most frequently used opioid; it provides effective analgesia but is associated with the possibility of inducing AEs such as nausea, vomiting, pruritus, and respiratory depression, which limits its use. ${ }^{7}$ Oxycodone is another promising opioid with regard to its adequate long-lasting analgesia and infrequent AEs. In Poland, oxycodone has primarily been administered via the oral route, until recently when ampoules for parenteral injections were made available. It is also occasionally used in central blockades with few studies regarding its effectiveness. Therefore, the aim of this study was to assess the analgesic efficacy and safety of oxycodone hydrochloride in epidural blockade among patients undergoing THA.

\section{Patients and methods}

The study protocol was approved by the Bioethical Committee at the Poznań University of Medical Sciences, Poland. The study was conducted in the Józef Struś Multiprofile Municipal Hospital in Poznan. All patients provided written, informed consent for their participation in the study.

The study included a total of 11 patients (mean age: $66 \pm 9$ years; body mass: $72 \pm 8 \mathrm{~kg}$ ) who underwent a total non-cemented hip arthroplasty by lateral access. The perioperative risk according to ASA (American Society of Anesthesiologists physical status classification system) was II in 7 patients and III in 4 patients (Table 1). In all the patients, the surgery was conducted owing to coxarthrosis. The following biochemical tests were conducted before the surgery: full blood count and plasma concentrations of sodium, potassium, creatinine (for eGFR calculation), urea, alanine aminotransferase, asparginate aminotransferase, total protein, and albumin (Table 2). Each patient received $7.5 \mathrm{mg}$ oral midazolam as premedication.

Upon arrival at the operating theater and the start of vitalsign monitoring (blood pressure, ECG, and pulse oximetry), the patient was fixed in a sitting position or on the side. After infiltration with $2 \mathrm{~mL} 2 \%$ lignocaine at the level of L3/L4 of the spine, the epidural space was identified with a Touhy 18 GA needle with the method of decreasing resistance by using $0.9 \% \mathrm{NaCl}$. Subsequently, a solution of $15 \mathrm{~mL} 0.25 \%$ bupivacaine (37.5 mg) and $5 \mathrm{mg}$ of oxycodone hydrochloride (OxyNorm ${ }^{\circledR}$ solution for injections; Mundipharma, Germany) were administered. When a satisfactory level of anesthesia was achieved after 30 minutes, the surgery was started with concurrent sedation using constant propofol infusion at a dose of 2-4 mg per $\mathrm{kg}$ of body weight per hour. The time of surgery and time after which patients were transferred to a post-anesthesia care unit (PACU) were measured. At the time of arrival into PACU, each patient received ketoprofen $100 \mathrm{mg}$ intravenously (IV) and subsequently the same dose

Table I Patients' basic demographic and clinical characteristics

\begin{tabular}{llllll}
\hline $\begin{array}{l}\text { Age } \\
\text { (years) }\end{array}$ & $\begin{array}{l}\text { Malel } \\
\text { female }\end{array}$ & $\begin{array}{l}\text { Body } \\
\text { weight }(\mathbf{k g})\end{array}$ & $\begin{array}{l}\text { Height } \\
(\mathbf{c m})\end{array}$ & $\begin{array}{l}\text { ASA } \\
\text { II/III }\end{array}$ & $\begin{array}{l}\text { Surgery } \\
\text { duration (min) }\end{array}$ \\
\hline $66 \pm 9$ & $3 / 8$ & $72 \pm 8$ & $168 \pm 7$ & $7 / 4$ & $100 \pm 15$ \\
\hline
\end{tabular}

Abbreviation: ASA, American Society of Anesthesiologists physical status classification system.

Table 2 Mean values of the laboratory parameters

\begin{tabular}{|c|c|}
\hline WBC (thousand $/ \mu \mathrm{L}$ ) & $8.58 \pm 1.16$ \\
\hline $\mathrm{Hb}(\mathrm{mmol} / \mathrm{L})$ & $8.16 \pm 0.93$ \\
\hline Hct (\%) & $39.7 \pm 4.6$ \\
\hline PLT (thousand $/ \mu \mathrm{L}$ ) & $250.17 \pm 83$ \\
\hline Albumin (g/L) & $27.1 \pm 2.7$ \\
\hline Protein $(g / L)$ & $53.5 \pm 6.1$ \\
\hline $\mathrm{Na}(\mathrm{mmol} / \mathrm{L})$ & $140.6 \pm 4.2$ \\
\hline $\mathrm{K}(\mathrm{mmol} / \mathrm{L})$ & $4.38 \pm 0.47$ \\
\hline Creatinine $(\mu \mathrm{mol} / \mathrm{L})$ & $64.7 \pm 26.4$ \\
\hline Urea (mmol/L) & $6.7 \pm 2.87$ \\
\hline ALT (U/L) & $14 \pm 7$ \\
\hline AST (U/L) & $13 \pm 1 \mid$ \\
\hline
\end{tabular}

Abbreviations: $\mathrm{Hb}$, hemoglobin; $\mathrm{HCT}$, hematocrit; PLT, platelet; WBC, white blood cell. 
of the drug after 12 hours. Pain intensity was assessed from 0 to 10 using the numerical rating scale (NRS; 0 : no pain and 10: the most severe pain), starting 3 hours after anesthesia and repeated every hour until 24 postoperative hours. According to a study protocol, patients could have received a rescue dose $(5 \mathrm{mg})$ of morphine administered subcutaneously (SC) in the case of reporting pain (NRS $>3$ ). The time of morphine rescue dose administration and pain intensity were registered. At the PACU, ECG, blood pressure, heart rate, and oxygen hemoglobin saturation were monitored.

Occurrence of AEs such as nausea, vomiting, pruritus, cognitive impairment, respiratory depression (decrease in the number of breaths to $<8$ per minute with concurrent decrease of saturation $<90 \%$ ), and possible neurologic disturbances such as sensation changes (lancinating and dull pain, tingling, and hyperesthesia) and their time interval were recorded. Patients were continuously observed for 24 hours following epidural bolus administration. Serum samples were obtained four times for quantification of total oxycodone and its metabolite noroxycodone after 30, 90, 150, and 210 minutes following the blockade and for the fifth time at the moment of morphine rescue dose administration.

\section{Results}

Patients' basic demographic and clinical data are summarized in Table 1. Mean values of the laboratory parameters of analyzed patients are presented in Table 2 . In all the patients, the laboratory parameters were within the normal range. No factors influencing metabolism and excretion of the drugs used were found.

The mean duration of postoperative analgesia equaled $10.3 \pm 4.89$ hours (minimum 5 hours, maximum over 24 hours). One patient did not need administration of a morphine rescue dose and his pain scores were $<4$ according to NRS in the 24 hours post-surgery. In another patient, mild pruritus was observed 3 hours after anesthesia administration, which resolved with $0.2 \mathrm{mg}$ naloxone IV. In 2 patients, bradycardia (heart rate $<45$ per minute) was observed 4 and 5 hours after anesthesia, respectively. No cognitive impairment, respiratory depression, nausea and vomiting, or other neurologic disturbances were seen in any of the patients.

Mean plasma concentrations of oxycodone and noroxycodone in patients after 30, 90, 150, 210 minutes following the blockade and at the moment of morphine rescue dose are shown in Table 3 and Figure 1. Plasma levels of oxycodone in patients during an effective analgesia period gradually

Table 3 Mean plasma oxycodone and noroxycodone concentrations in patients at 4 time points and at the moment of morphine rescue dose administration (mean: $618 \pm 293$ minutes)

\begin{tabular}{lll}
\hline $\begin{array}{l}\text { Time of assay } \\
\text { (minutes) }\end{array}$ & $\begin{array}{l}\text { Total oxycodone } \\
(\mathbf{n g} / \mathbf{m L})\end{array}$ & $\begin{array}{l}\text { Noroxycodone } \\
(\mathbf{n g} / \mathbf{m L})\end{array}$ \\
\hline 30 & $28.93 \pm 15.71$ & $3.11 \pm 2.30$ \\
90 & $22.64 \pm 16.70$ & $7.11 \pm 7.68$ \\
150 & $11.43 \pm 10.84$ & $2.21 \pm 0.76$ \\
210 & $4.03 \pm 8.23$ & $4.12 \pm 1.71$ \\
618 & $2.93 \pm 2.90$ & $1.89 \pm 0.19$ \\
\hline
\end{tabular}

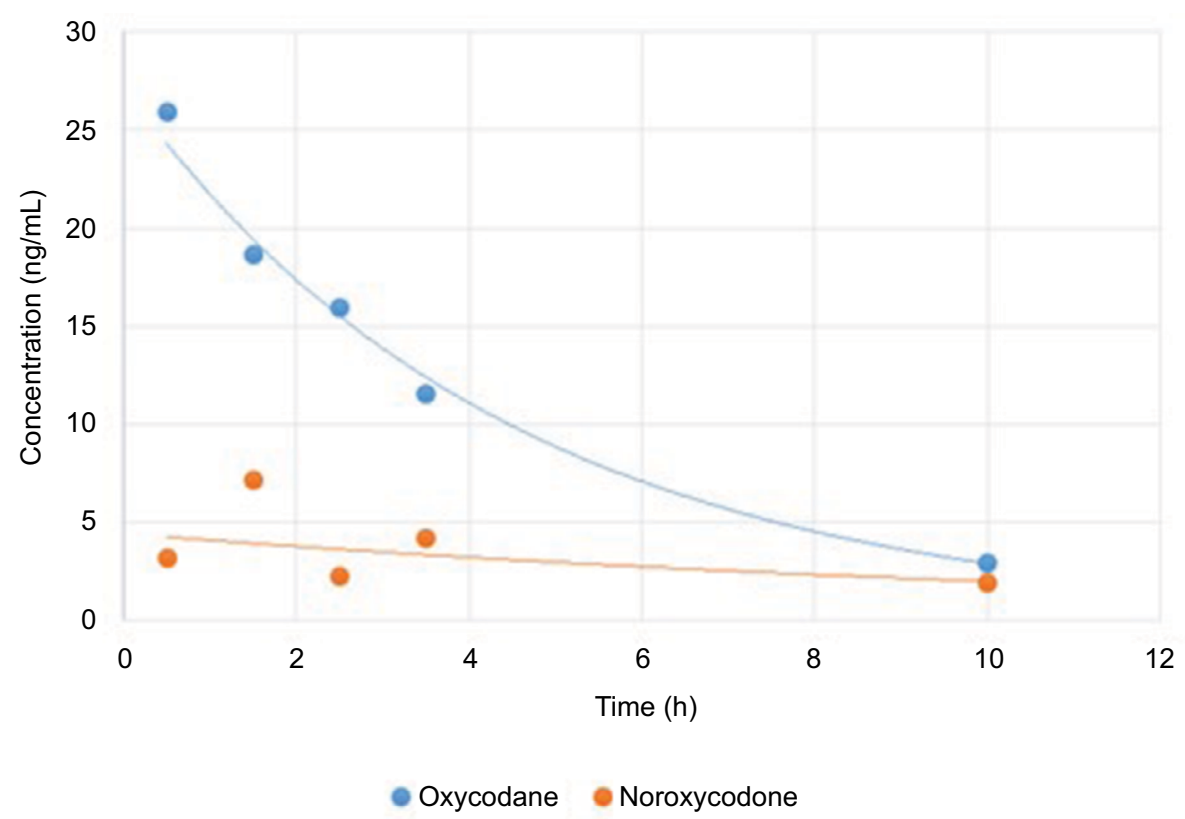

Figure I Mean plasma concentrations of oxycodone and noroxycodone after 30, 90, 150, and 210 minutes following the blockade and at the moment of morphine rescue dose administration (after mean: $618 \pm 293$ minutes since blockade). 


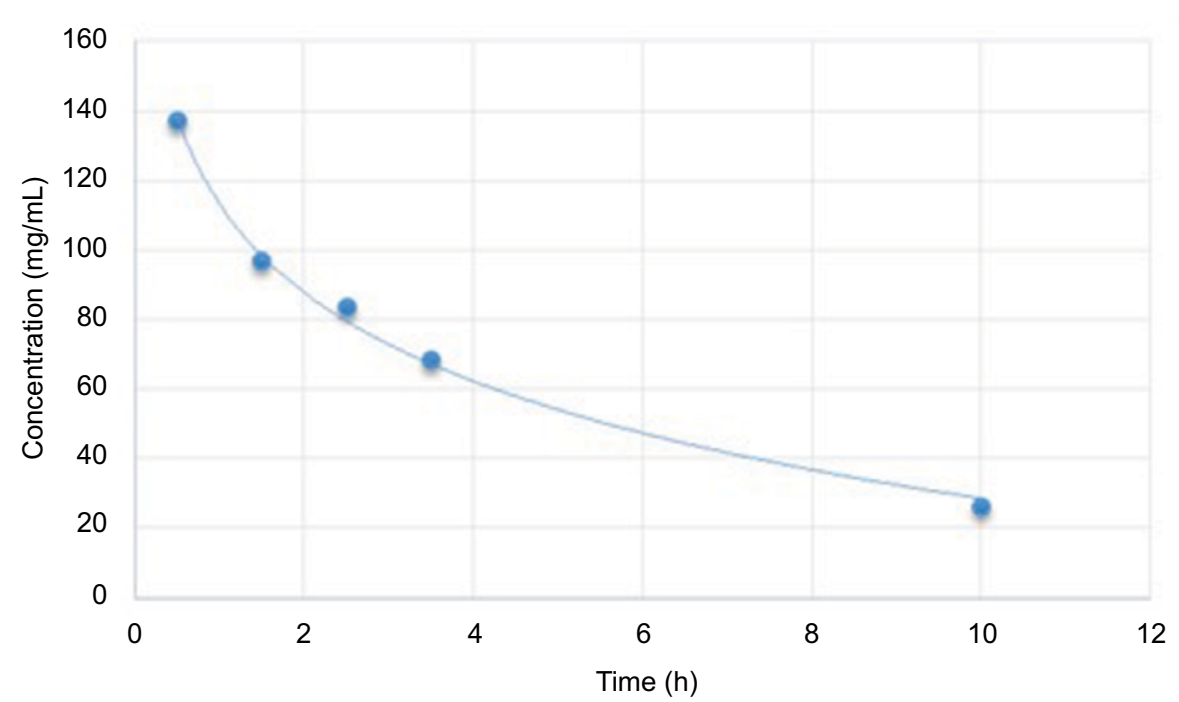

Figure 2 Mean plasma concentrations of bupivacaine after 30, 90, 150, and 210 minutes following the blockade and at the moment of morphine rescue dose administration (mean: 618 \pm 293 minutes since blockade).

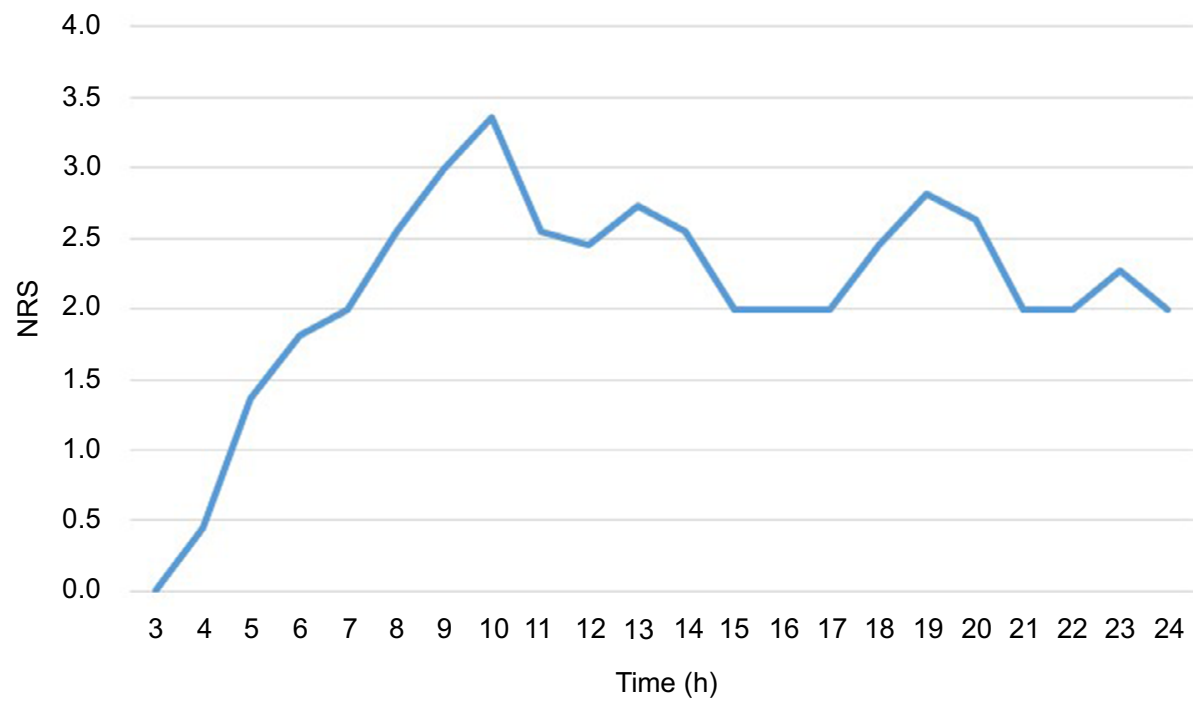

Figure 3 Mean numerical rating scale (NRS) score from 3 to 24 hours after administering epidural oxycodone $(n=I I)$.

decreased to $2.9 \mathrm{ng} / \mathrm{mL}$, at which patients requested a morphine rescue dose $(\mathrm{NRS}<3$ ). Plasma noroxycodone concentrations oscillated in the range of $1.9-7.1 \mathrm{ng} / \mathrm{mL}$.

Mean plasma bupivacaine concentration in patients after $30,90,150$, and 210 minutes following the blockade and at the moment of morphine rescue dose administration are shown in Figure 2. Mean NRS scores observed during the study period are shown in Figure 3.

\section{Discussion}

In this pilot study, administration of oxycodone in epidural blockade among patients suffering from coxarthrosis (Table 1) at a dose of $5 \mathrm{mg}$ with bupivacaine $(15 \mathrm{~mL}, 0.25 \%)$, combined with IV ketoprofen at a dose of $100 \mathrm{mg}$ every 12 hours administered postoperatively, prolonged the analgesia period until an approximate mean of $10.3 \pm 4.89$ hours (range: 5 to $>24$ hours). However, only one patient did not need the rescue dose of morphine administration and his pain scores were $<4$ according to NRS during 24 hours.

In this study, a dose of $5 \mathrm{mg}$ oxycodone was a fixed dose used in all patients. Taking into account their body mass, the dose was within a range of $0.06-0.08 \mathrm{mg} / \mathrm{kg}$ body mass, which is an indirect dose between those used by Backlund et al $(0.15 \mathrm{mg} / \mathrm{kg}$ in bolus and subsequent continuous infusion of $0.03 \mathrm{mg} / \mathrm{kg} / \mathrm{h})^{8}$ and that of Yanagidate et al (2 vs $4 \mathrm{mg}$ in bolus and subsequent continuous infusion of $6 \mathrm{vs} 12 \mathrm{mg} / 24 \mathrm{~h}$ ). ${ }^{9}$ 
It should be emphasized that no information regarding the length of analgesic effect of a single dose of oxycodone was provided in any of the cited studies.

To the best of our knowledge, no studies on epidural oxycodone administration in patients undergoing THA have so far been conducted. In a few published studies regarding oxycodone administration through the spinal and epidural routes, different analgesic effects were observed. Poyhia and Kalso showed that oxycodone spinal administration in a rat model rendered analgesia 14 times less effective than morphine. ${ }^{10}$ Backlund et al proved that in patients after abdominal surgery, the oxycodone epidural effective dose was 10 times greater than that of morphine: oxycodone was used at a dose of $0.15 \mathrm{mg} / \mathrm{kg}$ in bolus, and subsequently as a continuous infusion of $0.03 \mathrm{mg} / \mathrm{kg} / \mathrm{h} .{ }^{8}$ Yanagidate et al indicated that a twice-higher oxycodone dose administered epidurally provided comparable analgesia as with morphine in patients after gynecological surgery. ${ }^{9}$ Authors used a bolus of $2 \mathrm{mg}$ of morphine and 4 mg of oxycodone administered epidurally and subsequently maintained a continuous infusion of 6 and $12 \mathrm{mg}$ daily for 3 days, respectively.

In our study, plasma concentrations of oxycodone exceeded $10 \mathrm{ng} / \mathrm{mL}$ during the first 4 hours after epidural administration and could have influenced analgesia by the systemic effect. The analgesic effect of a bolus of oxycodone after IV administration is maintained for $\sim 4$ hours. ${ }^{11}$ Kokki et al compared concentrations of oxycodone and its metabolites in the serum and in cerebrospinal fluid after administration of oxycodone by both IV and epidural routes at a dose of $0.1 \mathrm{mg} / \mathrm{kg}$ of body weight. After epidural administration, oxycodone $\mathrm{c}_{\max }$ in the central nervous system was 350 times higher than that in the serum, while after IV administration, the ratio was 0.53 . Hence, neuraxial administration very likely renders effective analgesia with a lower dose of the drug than does IV administration. ${ }^{12}$

Opioid analgesia after systemic administration depends on the plasma opioid concentration. Kokki et al showed that in patients undergoing laparoscopic cholecystectomy, the minimum effective concentration (MEC) and minimum effective analgesic concentration (MEAC) of oxycodone administered by the IV route were $20-35$ and $45-50 \mathrm{ng} / \mathrm{mL}$, respectively. ${ }^{13}$ In a study conducted in patients after cardiac surgery, the MEC and MEAC were 6-12 and 15-25 ng/ml, respectively. ${ }^{14}$ These studies proved that oxycodone MEC and MEAC may significantly differ depending on the type of surgery. Among oxycodone metabolites, only oxymorphone displays a significant affinity to $\mu$ opioid receptors (14 times higher than that of oxycodone administered by a parenteral route), although its plasma concentrations are too low to exert clinical effects. Noroxycodone does not display significant analgesic effects. ${ }^{15}$

In our study, one patient experienced mild pruritus $\sim 3$ hours after anesthesia, which completely resolved after the administration of $0.2 \mathrm{mg}$ IV naloxone. A significantly lower percentage of patients treated with epidural oxycodone experienced pruritus and nausea than those treated with epidural morphine. ${ }^{9}$ In a recent study conducted among patients after caesarean section, postoperative analgesia was provided by oxycodone or morphine administered by the epidural route at a dose of $3 \mathrm{mg}$. Although oxycodone provided poorer analgesia, the percentage of patients with pruritus was lower than those who received morphine. ${ }^{16}$

In our study, 2 patients experienced bradycardia 4 and 5 hours after anesthesia, which resolved completely after administration of $0.5 \mathrm{mg}$ atropine and did not reappear. Bradycardia is observed in patients after epidural blockade without opioid administration even within a few hours of starting anesthesia; therefore, it cannot be unequivocally matched with oxycodone administration. ${ }^{17}$ Oxycodone at a dose of $5 \mathrm{mg}$ administered in the epidural space did not evoke other AEs in the patients studied.

The time of analgesic action of epidural bupivacaine blockade lasts $\sim 4$ hours and sometimes a little longer. The dose used in our study is often administered and depicted in many studies. ${ }^{18}$ The obtained concentrations of the drug are safe. ${ }^{19}$ Plasma bupivacaine concentrations are shown on Figure 2. Wolff et $\mathrm{al}^{20}$ administered $100 \mathrm{mg}$ bupivacaine (20 $\mathrm{mL} 0.5 \%$ bupivacaine) to the epidural space in THA. The dose rendered analgesia for a maximum period of 5 hours. The minimal time of analgesia ( 5 hours) in this study was associated with patients' different thresholds of pain sensation and the necessity for individual drug dose titration.

Studies regarding the use of the safest drugs in central blockades, both local anesthetics and so-called adjuvants that would guarantee a long period of analgesia, have been ongoing for a long time. Among the most frequently used are opioids, especially morphine, ${ }^{6,7}$ which may induce pruritus. The search for an opioid with the least number of AEs is still ongoing. In Poland, oxycodone has been traditionally administered by an oral route, and only recently SC and IV forms of administration have become available. ${ }^{21-24}$ However, alternatives to oral routes of administration of oxycodone are not very well understood. From studies conducted until now, it is evident that oxycodone analgesia depends on the route of administration. After IV adminis- 
tration, oxycodone displays $\sim 1.3$ times stronger analgesic effects than that of morphine during the first 24 hours after surgery. ${ }^{11}$ The consumption of oxycodone administered as patient-controlled analgesia (PCA) in patients after mastectomy was similar to morphine. ${ }^{21}$ In cancer patients, a ratio of the mean doses of morphine to oxycodone after $\mathrm{SC}$ administration equaled 1 to $2 \pm 0.4$, similar to after IV administration. ${ }^{22}$ Rectal administration of oxycodone in cancer patients rendered analgesia for $\sim 8-12$ hours, and the ratio of oxycodone to morphine was similar as for IV administration. ${ }^{23}$

In this study, morphine, which is a well-known and commonly used opioid often administered in our hospital in patients after THA, was chosen as the rescue opioid analgesic. Ten patients required a dose of $5 \mathrm{mg}$ of morphine administered SC that was effective in all cases.

To the best of our knowledge, this is the first clinical study of epidural oxycodone in patients undergoing THA, and this route of oxycodone administration is experimental. However, the period of analgesia and a safe dosing of oxycodone by an epidural route have not been established so far. In this pilot study, the plasma oxycodone concentration has been determined, which provides more insights into the drug's mode of action at the spinal level and its systemic effects. Limitations of the study include a small study sample and the study design (lack of randomization and a control group). No catheter for a continuous blockade was inserted due to the goal of possibly achieving long oxycodone analgesia, in accordance with the aims of the study.

\section{Conclusion}

The administration of oxycodone hydrochloride at a dose of $5 \mathrm{mg}$ in epidural blockade prolongs analgesia for a mean period of up to $\sim 10$ hours. Oxycodone may induce mild pruritus, but it does not evoke serious AEs such as respiratory depression, cognitive impairment, nausea and vomiting, or other neurologic disturbances. Oxycodone plasma concentrations may have an influence on systemic analgesia. Epidural oxycodone seems to be a safe method of pain relief for patients following THA. However, epidural administration should be considered experimental (off-label). Future larger controlled clinical studies to confirm our preliminary results regarding analgesic efficacy and safety of epidural route of oxycodone administration in patients with postoperative pain may be conducted.

\section{Disclosure}

The authors report no conflicts of interest in this work.

\section{References}

1. Central Database of total hip arthroplasty of the National Health Fund in Poland 2015. Available from: http://www.nfz.gov.pl/download/gfx/ nfz/pl/defaultstronaopisowa/349/30/1/cbe_za_2015.pdf. Accessed April 15, 2017. [Polish]

2. Bujedo BM, Santos SG, Azpiazu AU. A review of epidural and intrathecal opioids used in the management of postoperative pain. J Opioid Manage. 2012;8:177-192.

3. Brill S, Gurman GM, Fisher A. A history of neuraxial administration of local analgesics and opioids. Eur J Anaesthesiol. 2003;20:682-689.

4. Yaksh TL, Rudy TA. Analgesia mediated by a direct spinal action of narcotics. Science. 1976;192:1357-1358.

5. Wang JK, Nauss LA, Thomas JE. Pain relief by intrathecally applied morphine in man. Anesthesiology. 1979;50:149-151.

6. Behar M, Magora F, Olshwang D, Davidson JT. Epidural morphine in treatment of pain. Lancet. 1979;1:527-529.

7. Bujedo BM. A clinical approach to neuraxial morphine for the treatment of postoperative pain. Pain Res Treat. 2012;2012:612145

8. Backlund M, Lindgren L, Kajimoto Y, Rosenberg PH. Comparison of epidural morphine and oxycodone for pain after abdominal surgery. $J$ Clin Anesth. 1997;9:30-35.

9. Yanagidate F, Dohi S. Epidural oxycodone or morphine following gynaecological surgery. Br J Anaesth. 2004;93:362-367.

10. Poyhia R, Kalso EA. Antinociceptive effects and central nervous system depression caused by oxycodone and morphine in rats. Pharmacol Toxicol. 1992;70:125-130.

11. Poyhia R, Olkkola KT, Seppala T, Kalso E. The pharmacokinetics of oxycodone after intravenous injection in adults. Br J Clin Pharmacol. 1991;32:516-518.

12. Kokki M, Valitalo $P$, Kuusisto M, et al. Central nervous system penetration of oxycodone after intravenous and epidural administration. $\mathrm{Br} \mathrm{J}$ Anaesth. 2014;112:133-140.

13. Kokki M, Broms S, Eskelinen M, Rasanen I, Ojanpera I, Kokki H. Analgesic concentrations of oxycodone - a prospective clinical PK/ PD study in patients with laparoscopic cholecystectomy. Basic Clin Pharmacol Toxicol. 2012;110:469-475.

14. Pesonen A, Suojaranta-Ylinen R, Hammarén E, Tarkkila P, Seppälä T, Rosenberg PH. Comparison of effects and plasma concentrations of opioids between elderly and middle-aged patients after cardiac surgery. Acta Anaesthesiol Scand. 2009;53:101-108.

15. Kalso E. Oxycodone. J Pain Symptom Manage. 2005;29(5 Suppl):S47-S56.

16. Sng BL, Kwok SC, Mathur D, et al. Comparison of epidural oxycodone and epidural morphine for post-caesarean section analgesia: a randomised controlled trial. Ind J Anaesth. 2016;60:187-193.

17. Liguori GA, Sharrock, NE. Asystole and severe bradycardia during epidural anesthesia in orthopedic patients. Anesthesiology. 1997;86:250-257.

18. Macdowell AD, Robinson AH, Hill DJ, Villar RN. Is epidural anaesthesia acceptable at total hip arthroplasty? Bone Joint J. 2004;86:1115-1117.

19. Dillane D, Finucane BT. Local anesthetic systemic toxicity. Can J Anaesth. 2010;57:368-380.

20. Wolff AP, Hasselstrom L, Kerkkamp HE, Gielen MJ. Extradural ropivacaine and bupivacaine in hip surgery. Br J Anaesth. 1995;74:458-460.

21. Silvasti M, Rosenberg P, Seppala T, Svartling N, Pitkanen M. Comparison of analgesic efficacy of oxycodone and morphine in postoperative intravenous patient-controlled analgesia. Acta Anaesthesiol Scand. 1998;42:576-580

22. Gangon B, Bielech M, Watanabe S. The use of intermittent subcutaneous injections of oxycodone for opioid rotation in patients with cancer pain. Support Care Cancer. 1999;7:265-270.

23. Leow KP, Cramond T, Smith MT. Pharmacokinetics and pharmacodynamics of oxycodone when given intravenously and rectally to adult patients with cancer pain. Anesth Analg. 1995;80:296-302.

24. Olczak B, Kowalski G, Leppert W, Zaporowska-Stachowiak I, Wieczorowska-Tobis K. Analgesic efficacy, adverse effects, and safety of oxycodone administered as continuous intravenous infusion in patients after total hip arthroplasty. J Pain Res. 2017;10:1027-1032. 
The Journal of Pain Research is an international, peer reviewed, open access, online journal that welcomes laboratory and clinical findings in the fields of pain research and the prevention and management of pain. Original research, reviews, symposium reports, hypothesis formation and commentaries are all considered for publication
The manuscript management system is completely online and includes a very quick and fair peer-review system, which is all easy to use. Visit http://www.dovepress.com/testimonials.php to read real quotes from published authors. 